\title{
Online Determination of the Enantiomer Concentration Using HPLC Coupled with UV and Circular Dichroism Detectors
}

\author{
Hui Li, Yongtao Chen, Xiaoxiao Jiang \\ College of Chemistry and Material Engineering \\ Wenzhou University \\ Zhejiang Wenzhou, China \\ 18266186378@163.com
}

\begin{abstract}
The application of ultraviolet absorption detector (UV) and circular dichroism (CD) detectors in series in HPLC systems has been increased in recent years. In this work, an effective method to determine the enantiomer concentration on line in chiral drugs was explored. Ibuprofen (IBP) racemate was applied. The total concentration and concentration difference of S-(+)-IBP and R-(-)-IBP were obtained by the online monitoring systems in HPLC systems. The single enantiomer respective concentrations were also calculated. The UV and CD detectors in series as the online monitoring systems to determine the enantiomer concentration was applied. This method is gradually developed into a practical tool for enantiomeric purity analysis. A new method which can fit the two components respectively rather than both components in the fitting procedure of Inverse method (IM) was provided. This research shows that a commercially available UV and CD detectors in series can be successfully used to determine the enantiomer concentration.
\end{abstract} IBP

Keywords: UV; CD; HPLC; enantiomer concentration;

\section{INTRODUCTION}

Enantiomeric purity analysis of enantiomers online is very important in the process control of pharmaceutical industry due to their different biological activities ${ }^{[1]}$, while having the same physical and chemical properties ${ }^{[2]}$. In this work, the UV and CD detectors in series as the online monitoring systems to determine the enantiomer concentration was applied. The total concentration and concentration difference of S-(+)-IBP and R-(-)-IBP at the specific time were monitored by the online monitoring systems in HPLC systems. HPLC, especially preparative HPLC, has triggered ever increasing attention in the last decade. The usefulness of $\mathrm{CD}$ detector is due to its selectivity (the detector will "observe" only chiral molecules) and to the fact that positive and negative signals can be obtained ${ }^{[3-4]}$. HPLC coupled with CD detection was firstly applied to measure enantiomeric purity in $1980^{[5]}$. This method is gradually developed into a practical tool for enantiomeric purity analysis.

Inverse method (IM), a numerical method, was developed recently to determine isotherm, common of two compounds, with the help of computer technology by fitting overload band profiles ${ }^{[6-7]}$. The IM, as a relatively new method its accuracy has been proved. The most distinguishing feature of this research was to provide a new method which can fit the two components respectively rather than both components in the fitting procedure. During the process, the overload band profiles were needed and this method could measure the single enantiomer respective concentrations. Elution profiles of R-(-)-IBP and S-(+)-IBP were obtained.

IBP is an significant non-steroidal anti-inflammatory drug (NSAID) marked as a racemic of the 2-arylpRopionic acid group used for the treatment of a variety of rheumatic and musculoskeletal disease states. IBP shows stereoselectivity in both action and disposition ${ }^{[8]}$. The $\mathrm{S}$ $(+)$-IBP plays a major role, and the other enantiomer is relatively inactive. So, separation of IBP enantiomers is of significance.

\section{THEORETICAL}

Enantiomeric concentration with chiral separation is based on the use of UV and CD detectors in series at a fixed wavelength. The UV response is proportional to the total concentration $\left(C_{R}+C_{S}\right)$. The $C D$ response is proportional to concentration difference of $\mathrm{S}-(+)-\mathrm{IBP}$ and R-(-)-IBP $\left(\mathrm{C}_{\mathrm{R}}-\mathrm{C}_{\mathrm{S}}\right.$ or $\left.\mathrm{C}_{\mathrm{S}}-\mathrm{C}_{\mathrm{R}}\right){ }^{[9-10]}$. Thus, the $\mathrm{M}_{\mathrm{R}}$ and $\mathrm{M}_{\mathrm{S}}$ can be obtained, where $M_{R}$ is the mass of the R-(-)-IBP enantiomer and the $M_{S}$ is the mass of the $\mathrm{S}-(-)-\mathrm{IBP}$ enantiomer.

In the present note it is shown how the above can be applied to determine the enantiomer consideration from a HPLC column, using the data coming from the online monitoring systems UV and CD detectors in series.

\section{EXPERIMENTS}

\section{1 chemicals and Instruments}

HPLC grade n-hexane (>95\%) and 2-Propanol (IPA) $(>99.9 \%)$ were produced by Sigma-Aldrich. Spectrophotometric grade TFA with a purity $>99 \%$, was obtained from Merck (Darmstadt, Germany). Ibuprofen racemic mixture $(>98 \%)$ and S- $(+)$-Ibuprofen $(>98 \%)$ were purchased from J\&K. 1, 3, 5-tri-tert-butylbenzene (TTBB $>98 \%$ ) were purchased from TCI.

An Agilent 1260 series chromatography (consist of a binary HPLC pump, a flow splitter, a chromatography column, a UV detector and a computer for data analysis); UV-2450 Shimadzu Corp. Japan; circular dichroism (CD); superheated water bath; electronic balance; Pipette; 
ultrasonic cleaning machine; solution filters; Chiralcel-OD $(100 \mathrm{~mm} \times 10 \mathrm{~mm}, 20 \mu \mathrm{m})$ column, Daicel Chemical Industries, Ltd., Japan.

\subsection{Experimental Conditions}

Stationary phase: Chiralcel-OD column; Mobile phase: hexane/IPA/TFA $=99 / 1 / 0.01 \% \quad(\mathrm{~V} / \mathrm{V} / \mathrm{V}) ; \quad$ Column temperature: $25^{\circ} \mathrm{C}$. The extra column volume of the HPLC system and the total void fraction of Chiralcel-OD column were $0.52 \mathrm{~mL}$ and 0.71 respectively, measured by TTBB pulse experiments.

In order to further validate the determined experimental data from $\mathrm{CD}$ detector, the $\mathrm{CD}$ absorption signal at different flow rates from 0 to $1.5 \mathrm{~mL} \cdot \mathrm{min}^{-1}$ was measured (S-(+)-IBP as the sample). Fig .1 shows the stability of the $\mathrm{CD}$ detector.

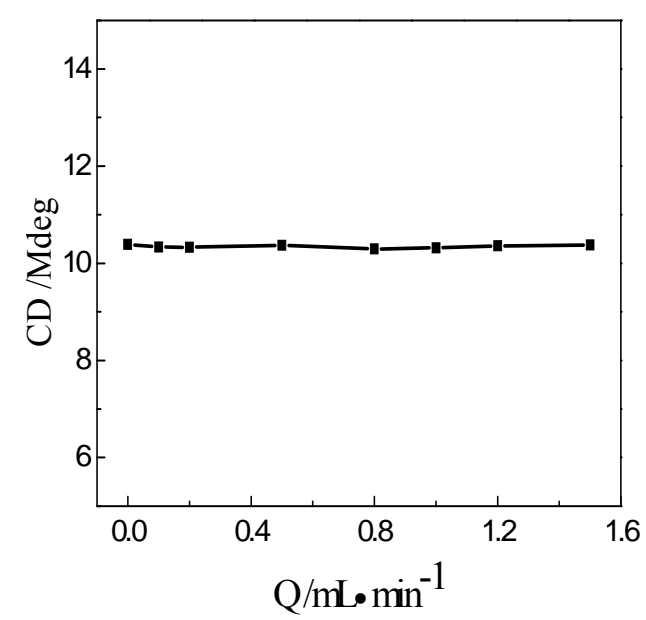

Figure 1. $\mathrm{CD}$ absorption signal at different flow rates from 0 to 1.5 $\mathrm{mL} \cdot \mathrm{min}^{-1}$

\subsection{UV and CD Scanning}

UV and CD adsorption to S-(+)-IBP were screened over a wavelength range of 190-800 nm using a UV Recording Spectrophotometer and the circular dichroism. In order to ensure the sensitivity both of UV and CD detectors at the same time, the best sensitivity was chose at the wavelength of $227 \mathrm{~nm}$, which was then used for sample analysis and linear range measurements. In the case of overloaded band profile measurements, a less sensitive wavelength of 254 nm was used to avoid UV response signals beyond the measuring range at high concentrations, while $\mathrm{CD}$ detector kept the same wavelength as linear range. The S- $(+)-$ IBP as the sample was chose to get the calibration curves ignoring the R-(-)-IBP due to they were symmetrical with origin and no peak would be shown for racemate in $C D$ spectrogram.

\subsection{UV and CD Calibration Curves}

The calibration curves for UV at the $254 \mathrm{~nm}$ wavelength and $\mathrm{CD}$ at the $227 \mathrm{~nm}$ wavelength were shown in Fig .2(a), Fig .2 (b).:

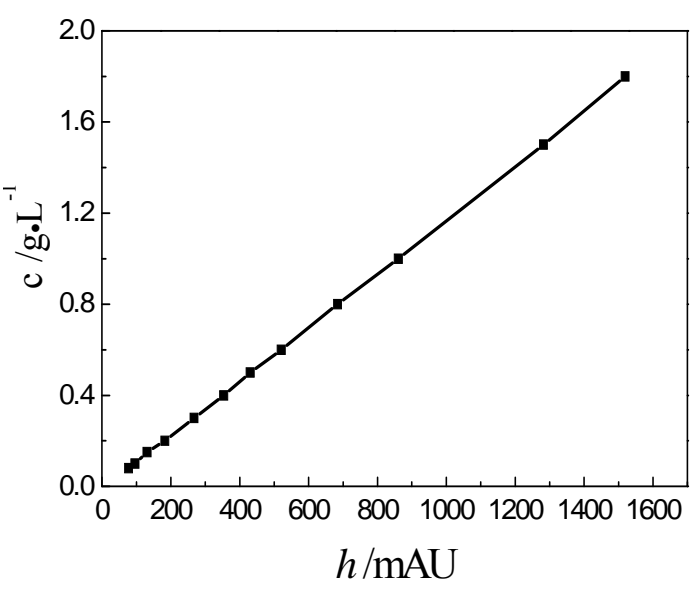

Figure 2 (a). UV calibration curve at the wavelength of $254 \mathrm{~nm}$

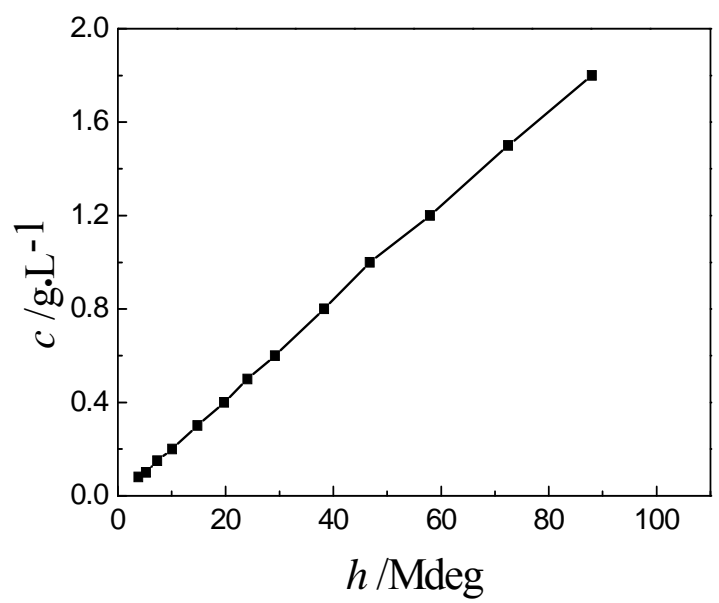

Figure 2 (b). CD calibration curve at the wavelength of $227 \mathrm{~nm}$

The Calibration curves equation are:

$$
\begin{aligned}
& c=1.20 \times 10^{-3} h \quad\left(254 \mathrm{~nm}, \mathrm{R}^{2}=0.9993\right) \\
& c=2.07 \times 10^{-2} h\left(227 \mathrm{~nm}, \mathrm{R}^{2}=0.9995\right)
\end{aligned}
$$

Among them, $\mathrm{c}$ is the concentration of the solution of $\mathrm{s}-(+)$-IBP, $\mathrm{g} \cdot \mathrm{L}^{-1} ; h$ is the electrical signal, $\mathrm{mAU}$.

\subsection{The Experiment of Overloaded Band Profiles}

The experimental setup is plotted in Fig .3. The vials equipped with mobile phase and the IBP racemic samples were connected with the elution pump and injector pump, respectively. The rectangular feeds were provided to Chiralcel-OD column by computer software language. Elution profiles of various racemic feed signals were measured on a preparative chromatography column with a precise temperature control system. The data were determined by UV and CD signals, respectively. The overloaded band profiles were shown in Fig .4 (a). and Fig .4 (b). ( flow rate: $1.0 \mathrm{ml} \cdot \mathrm{min}^{-1}$; the injection: $6 \mathrm{mg}$; concentration: $\mathrm{c}=20 \mathrm{~g} \cdot \mathrm{L}^{-1}$ ), the single enantiomer respective concentrations were shown in Fig .5 and the mass balance for components in the column was described in TABLE I. 


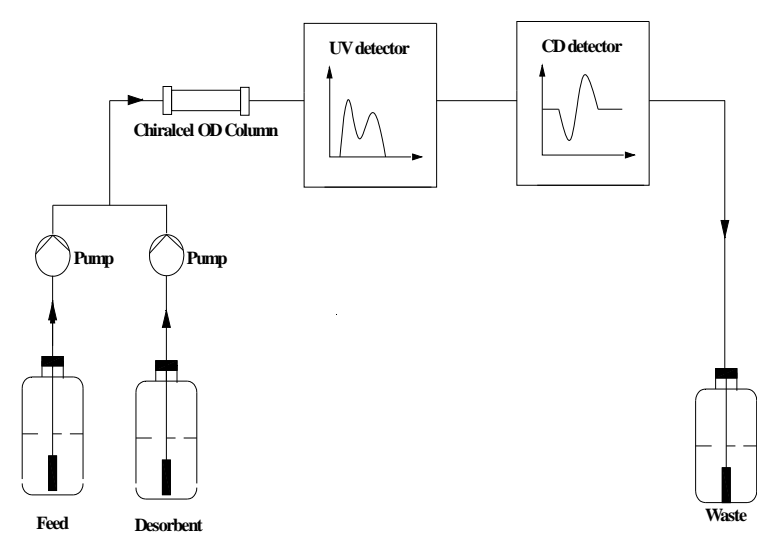

Figure 3. Schematic diagram of experimental setup for overload elution profile measurements

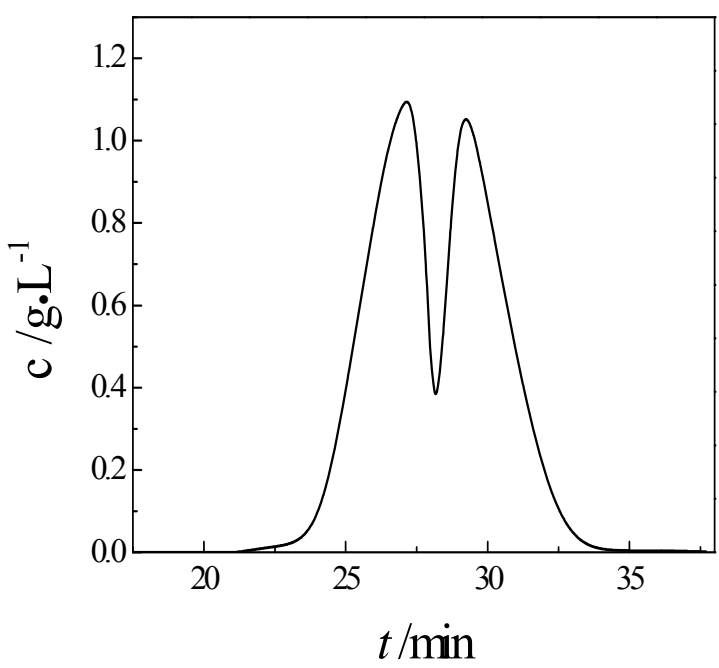

Figure 4 (a). Overload profile of IBP racemic samples from UV detector

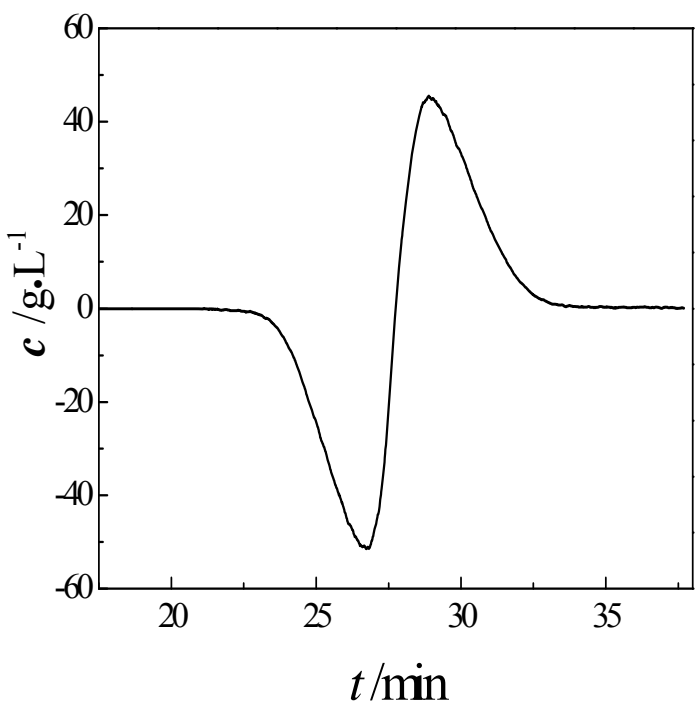

Figure 4 (b). Overload profile of IBP racemic samples from CD detector

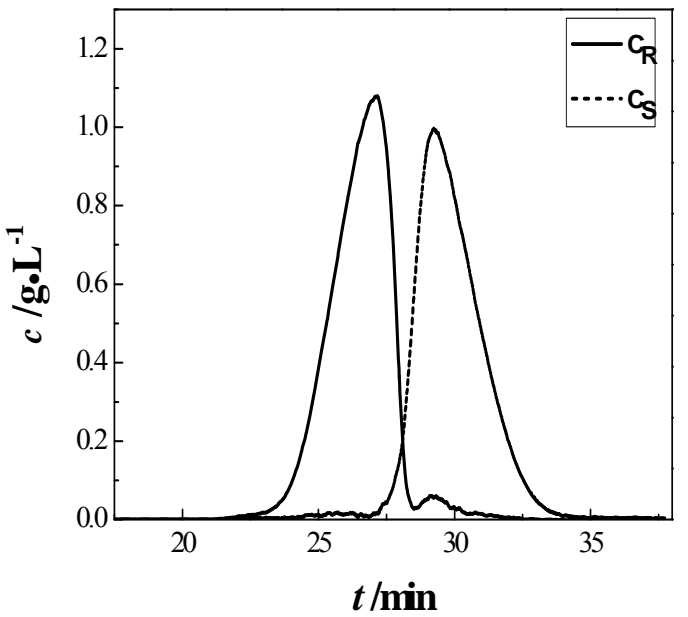

Figure 5. Elution profiles of R-(-)-IBP and S-(+)-IBP

TABLE I. THE MASS BALANCE FOR COMPONENTS IN THE COLUMN BY HPLC-UV-CD IN SERIES

\begin{tabular}{|c|c|c|c|c|c|}
\hline $\begin{array}{c}C / \\
g \cdot L^{-1}\end{array}$ & $\begin{array}{c}\mathbf{Q} \\
/ \mathbf{m L}^{-} \\
\mathbf{m i n}^{-1}\end{array}$ & $\begin{array}{l}\text { Inject/ } \\
\text { mg }\end{array}$ & $\begin{array}{l}\text { R- } \\
(-)- \\
\text { IBP/ } \\
\text { mg }\end{array}$ & $\begin{array}{l}\text { S- } \\
(+)- \\
\text { IBP/ } \\
\text { mg }\end{array}$ & $\begin{array}{l}\text { Relative } \\
\text { error \% }\end{array}$ \\
\hline 10.0 & 1.00 & 3.00 & 1.56 & 1.50 & 3.80 \\
\hline 10.0 & 1.50 & 3.45 & 1.77 & 1.78 & 0.56 \\
\hline 10.0 & 2.00 & 4.60 & 2.30 & 2.28 & 0.87 \\
\hline 15.0 & 1.00 & 4.50 & 2.23 & 2.20 & 1.30 \\
\hline 20.0 & 1.00 & 5.50 & 2.72 & 2.71 & 0.36 \\
\hline
\end{tabular}

\section{CONCLUSIONS}

In summary, we have developed an effective method to determine the enantiomer concentration in the chiral drugs . The accuracy and reliability has been proven by the mass balance (relative error less than 4\%). The result discussed above shows that a commercially available UV and $\mathrm{CD}$ detectors in series can be successfully used to determine the enantiomer concentration.

\section{ACKNOWLEDGMENT}

This work was supported by National Natural Science Foundation of China (grant No.211- 06108).

\section{REFERENCES}

[1] F. Jamali, R. Mehvar, F. M. Pasutto., "Enantioselective aspects of drugsaction and disposition", therapeutic pitfalls. J Pharm Sci, vol. 78, pp. 695-715, 1989.

[2] M. T. Miller, Z H Ge, and B. Mao. "Development of a Nonchiral HPLC Method with Circular Dichroism Detection for Chiral Analysis of Molybdenum Catalyzed Enantioselective Synthesis Products,” CHIRALITY. vol. 14, pp. 659-664, 2002.

[3] S. Piero, R. Carlo, B. Carlo. "Circular Dichroism Detection in the HPLC of Chiral Molecules: Direct Determination of Elution Orders," J.Org.Chem, vol.49, pp. 5050-5054, 1984. 
[4] S. Song, L. Sun, L. Yuan, T. Sun, Y. Zhao,W. J. Zuo, Y. Cong, X. $\mathrm{Li}$ and J. H. Wang, "Method to determine enantiomeric excess of glucose by nonchiral high-performance liquid chromatography using circular dichroism detection," Journal of Chromatography A, vol. 1179, pp. 125-130, 2008

[5] A. F. Drake, J. K .Gould, S. F. Mason., "simultaneous monitoring of ligh-absorption and optical activity in the liquid chromatography of chiral substance," J Chromatogr., vol. 202, pp. 239-245, 1980.

[6] M. James,. I.. Sepúlveda, Quiñones, et al., "Determination of binary competitive equilibrium isotherms from the individual chromatographic band profiles," Chem. Eng. Sci, vol. 54, pp.16771696, 1999.

[7] J. Xu, L. Zhu, Guoqian Xu, W. F. Yu and A. K. Ray*, "Determination of competitive adsorption isotherm of enantiomers on preparative chromatographic column using inverse method," Journal of Chromatography A, vol. 1273, pp. 49-56,2013.
[8] Soo Choon Tan, James A. Baker, Nichola Stevens, Vern Biasi, Colin Salter, Maria Chalaux, Kamyar Afarinkia and Andrew J Hutt, "chromatographic resolution and chiroptical properties of carboxyibuprofen stereoisomers: major metabolites of ibuprofen in man," Synthesis, vol. 9, pp. 75-87, 1997.

[9] R. C. William, J. F. Edward, A. S. Joshi, Ann Francoise Aubry. "Chiral analysis of drug substance in clinical plasma extracts using achiral HPLC with circular dichroism detection.," Journal of Pharmaceutical and Biomedical Analysis, vol. 25, pp. 501-509, 2001.

[10] L. Kott, W. Brian Holzheuer, Megan M. Wong, Gregory K. Webster. "An evaluation of four comercial HPLC chiral detectors: A comparison of three polarimeters and a circular dichroism detector," Journal of Pharmaceutical and Biomedical Analysis, vol. 43 , pp.57-65, 2007. 